\title{
НЕЙРОСЕТЕВОЕ МОДЕЛИРОВАНИЕ IRAК1-ИНГИБИРУЮЩЕЙ АКТИВНОСТИ ХИМИЧЕСКИХ СОЕДИНЕНИЙ НА ОСНОВЕ ИХ СТРУКТУРНЫХ И КВАНТОВО-ХИМИЧЕСКИХ ДЕСКРИПТОРОВ
}

\author{
А.В. Голубева ${ }^{1}$, П.М. Васильев ${ }^{2,1}$, Д.А. Бабков ${ }^{2,1}$, А.Н. Кочетков ${ }^{2}$ \\ ${ }^{1}$ Кафедра фармакологии и биоинформатики, ФГБОУ ВО ВолгГМУ \\ Минздрава России, 400001, Россия, г. Волгоград, ул. Ким, д. 20. \\ ${ }^{2}$ Научный центр инновационных лекарственных средств, ФГБОУ ВО ВолгГМУ Минздрава \\ России, 400087, Россия, г. Волгоград, ул. Новороссийская, 39.
}

DOI: 10.19163/MedChemRussia2021-2021-183_E-mail:arina_arina_golubeva@mail.ru

Целью работы явилось построение с помощью технологии искусственных нейронных сетей модели зависимости IRAK1-ингибирующей активности химических соединений от их структурных и квантово-химических параметров.

Создана база данных по структуре и активности 1127 известных ингибиторов IRAK1. Градации уровней активности были определены путем объединения сходных методик и последующей кластеризации. С использованием системы IT Microcosm v7.3 сформировано описание структуры этих соединений дескрипторами 1-го ранга языка QL. C помощью программы MOPAC2016 рассчитаны пять квантово-химических параметров указанных молекул. При построении зависимостей между двумя уровнями IRAK1-ингибирующей активности (высокой и выраженной) и структурно-квантово-химическим описанием соединений использовали технологию искусственных нейронных многослойных перцептронных сетей. Обучение проводили в стандартном режиме программы Statistica 12. Для каждого уровня активности рассчитывали по 200 сетей, с последующим проведением ROC-анализа и тестированием точности на объединенной выборке.

Найдены оптимальные по точности нейронные сети со следующими характеристиками прогностической способности: ROC=93,4\%, $\mathrm{F}_{0}=95,4 \%$, $F_{a}=85,6 \%, F_{n}=97,3 \% ; R O C=92,7 \%, F_{0}=91,7 \%, F_{a}=91,3 \%, F_{n}=91,9 \%$ - для уровней IRAK1-ингибирующей активности «высокая» и «выраженная», соответственно. Использование при обучении совместно структурных и квантово-химических дескрипторов позволило существенно повысить точность прогноза IRAK1-ингибирующей активности.

Построены высокоточные нейросетевые зависимости IRAK1ингибирующей активности химических соединений от их структурных и квантово-химических дескрипторов. Полученные модели используются в направленном поиске лекарственных веществ, блокирующих развитие цитокинового шторма при осложнении COVID-инфекции.

Работа выполнена при финансовой поддержке гранта Минобрнауки РФ № 075-15-20-777. 